\title{
GENE EXPRESSIONS INVOLVED IN IMMUNE SYSTEM CONTROL AND SERUM CA125 CONTENT IN POLYCYTHEMIA VERA
}

\author{
Do Thi Trang ${ }^{1}$, Nguyen Thi Xuan ${ }^{1,2, *}$ \\ ${ }^{1}$ Institute of Genome Research, VAST, Vietnam \\ ${ }^{2}$ Graduate University of Science and Technology, VAST, Vietnam
}

Received 9 December 2019, accepted 4 March 2020

\begin{abstract}
Polycythemia Vera (PV) is a slowly progressing blood cancer associated with myeloproliferative neoplasms. The disease is characterized by an abnormal proliferation of three cell types including red blood cells, white blood cells and platelets and a symptom of pruritus caused by release of itching agents of activated mast cells. The enhanced expression of several genes involved in immune system control including $C T L A-4, P D-1$ and $L A G 3$ are linked to activation immune tolerance. Klotho gene has anti-aging, anti-inflammation and anti-cancer functions. The SHP gene group belongs to the tyrosine phosphatase protein signaling family that regulates cancer cell proliferation through maturation, migration and apoptosis and includes two main genes, SHP-1 and $S H P-2$. The increased serum content of cancer antigen CA125 is considered as a cancer marker of several blood and hematopoietic disorders. In this study, we conducted experiments to determine mRNA expression of above genes in PV patients by realtime-PCR and CA125 concentration by ELISA. Results showed that expression of klotho, LAG3, CTLA-4 and PD-1 genes was decreased in PV patients, indicating that the immune tolerance was inactivated in PV patients. CA125 concentration was significantly increased in PV patients compared to healthy individuals and interestingly, there was a positive association among three patients, who having increased CA125 concentration and biochemical indicators including LDH, AST and ALT. The results in this study provide an important reference document for further studies that serve for the early detection of PV disease.
\end{abstract}

Keywords: Anti-aging function, blood cancer, immune checkpoints, polycythemia vera.

Citation: Do Thi Trang, Nguyen Thi Xuan, 2020. Gene expressions involved in immune system control and serum CA125 content in polycythemia vera. Tap chi Sinh hoc, 42(1): 103-110. https://doi.org/10.15625/0866$7160 / \mathrm{v} 42 \mathrm{n} 1.14677$.

*Corresponding author email: xuannt@igr.ac.vn

C2020 Vietnam Academy of Science and Technology (VAST) 


\title{
BIỂU HIỆN MỘT SỐ GEN KIỂM SOÁT MIỄN DỊCH VÀ NỒNG Độ CA125 Ở BỆHH NHÂN TĂNG HỒNG CẦU VÔ CĂN
}

\author{
Đỗ Thị Trang ${ }^{1}$, Nguyễn Thị Xuân ${ }^{1,2, *}$ \\ ${ }^{1}$ Viện Nghiên cứu hệ gen, Viện Hàn lâm Khoa học và Công nghệ Việt Nam \\ ${ }^{2}$ Học viện Khoa học và Công nghệ, Viện Hàn lâm Khoa học và Công nghệ Việt Nam
}

Ngày nhận bài 9-12-2019, ngày chấp nhận 4-3-2020

\section{TÓM TÁT}

Tăng hồng cầu vô căn (THCVC) là bệnh ung thư máu tiến triển chậm, liên quan đến tăng sinh tủy ác tính. Bệnh liên quan đến sự tăng sinh bất thường của 3 dòng tế bào, gồm hồng cầu, bạch cầu và tiểu cầu và triệu chứng ngứa điển hình do kích hoạt tế bào mast cell tiết ra chất gây ngứa. Một số gen tham gia kiểm soát miễn dịch bao gồm $C T L A-4, P D-1$ và $L A G 3$, biểu hiện tăng cao liên quan đến hoạt động của hệ miễn dịch đối kháng. Gen klotho có chức năng chống lão hóa, viêm và ung thư. Nhóm gen $S H P$ là những gen thuộc họ tín hiệu protein tyrosine phosphatase điều hòa sự tăng sinh tế bào ung thư thông qua sự thuần thục, sự di cư và sự chết apoptosis, gồm hai loại gen chính là $S H P-1$ và $S H P-2$. Nồng độ kháng nguyên ung thư CA125 tăng lên trong máu được sử dụng như một chỉ thị sinh học trong chẩn đoán một số bệnh ung thư máu và cơ quan tạo máu. Trong nghiên cứu này, chúng tôi tiến hành xác định biểu hiện mRNA của các gen này trên bệnh nhân $\mathrm{THCVC}$ bằng kỹ thuật realtime-PCR và nồng độ $\mathrm{CA} 125$ bằng kỹ thuật ELISA. Kết quả cho thấy, biểu hiện các gen klotho, LAG3, CTLA-4 và $P D-1$ giảm xuống ở bệnh nhân THCVC chỉ ra hệ miễn dịch đối kháng chưa hoạt động. Nồng độ CA125 tăng cao rõ rệt so với người khỏe và 3 bệnh nhân có nồng độ CA125 tăng tỷ lệ thuận với chỉ số hóa sinh $\mathrm{LDH}$, AST và ALT trong máu người bệnh. Kết quả nghiên cứu này là tài liệu tham khảo quan trọng cho nghiên cứu tiếp theo giúp chẩn đoán phát hiện sớm ung thư THCVC.

Từ khóa: Chống lão hóa, kiểm soát miễn dịch, tăng hồng cầu vô căn, ung thư máu.

*Địa chỉ liên hệ email: xuannt@igr.ac.vn

\section{MỞ ĐẦU}

Tăng hồng cầu vô căn (THCVC) là bệnh ung thư máu thuộc nhóm bệnh tăng sinh tủy ác tính, được đặc trưng bởi một số đặc điểm như: sự tăng sinh mất kiểm soát của 3 dòng tế bào hồng cầu, bạch cầu và tiểu cầu và không có nhiễm sắc thể Philadelphia $(\mathrm{Ph})$ chứa tổ hợp gen $\mathrm{BCR}-\mathrm{ABL} 1$. Những đặc điểm này là tiêu chuẩn quan trọng để phân biệt với nhóm bệnh ung thư máu khác như bệnh bạch cầu dòng tủy và bệnh bạch cầu dòng lympho (Hehlmann et al., 2007). Nhiễm sắc thể $\mathrm{Ph}$ này là nguyên nhân dẫn đến hiện tượng kích hoạt tự phát các tín hiệu phân tử tyrosine kinase và phosphatase làm tế bào tăng sinh một cách bất thường (Hantschel et al., 2012). THCVC thường phát triển chậm và có đặc điểm ngứa là đặc trưng được tìm thấy trong khoảng $40 \%$ bệnh nhân THCVC, đặc biệt sau khi bệnh nhân tiếp xúc với nước ấm. Đặc điểm ngứa của bệnh nhân được giải thích là do sự giải phóng histamine (Siegel et al., 2013) và prostaglandin (Afrin, 2011) bất thường vào máu. Một trong những nguyên nhân di truyền là đột biến gen JAK2/JAKl, dẫn đến tăng biểu hiện protein JAK2/JAK1 và kích hoạt tế bào mast cell giải phóng các chất gây ngứa (Afrin, 2011; Siegel et al., 2013). 
Các gen tham gia kiểm soát miễn dịch bao gồm gen cytotoxic T-lymphocyte-associated antigen $4(C T L A-4)$, programmed cell death 1 $(P D-1)$ và lymphocyte-activation gene 3 (LAG3) hiện nay được chú trọng nghiên cứu rộng rãi trên nhiều loại bệnh ung thư khác nhau, trong đó có ung thư máu. Ba gen này biểu hiện với mật độ cao trên tế bào $\mathrm{T}$ điều hòa và cảm ứng hoạt hóa tế bào này, vì thế biểu hiện của chúng tăng cao bất thường gây ra sự can kiệt về số lượng và chất lượng của tế bào $\mathrm{T}$ hỗ trợ, đồng thời kích hoạt tế bào $\mathrm{T}$ điều hòa tăng sinh và hoạt hóa với số lượng lớn và tế bào $\mathrm{T}$ helper 17 cells (Th17) tới vị trí khối u tạo ra hệ miễn dịch đối kháng và ức chế sự phát triển của các loại tế bào $\mathrm{T}$ gây độc và tế bào diệt tự nhiên (Buchbinder et al., 2015; Kitamura et al., 2015). Đây là nguyên nhân phổ biến gây ra tình trạng hệ miễn dịch không hoạt động tạo điều kiện cho tế bào ung thư phát triển nhanh chóng. Chính vì vậy, điều trị hóa trị ung thư hiện nay có kết hợp với sử dụng thuốc ức chế các điểm kiểm soát miễn dịch này làm tăng hiệu quả điều trị bệnh rõ rệt (Buchbinder et al., 2016; He et al., 2016). Trong số 3 gen trên, vai trò điều hòa hoạt động hệ miễn dịch trên bệnh nhân ung thư của gen $L A G 3$ được phát hiện muộn nhất và vẫn còn đang là vấn đề lớn cần nghiên cứu kỹ hơn. Gen $L A G 3$ tham gia ức chế hoạt động của tế bào tua, từ đó cảm ứng hệ miễn dịch đối kháng thông qua sự gắn kết với phân tử biểu hiện kháng nguyên MHC II, vì thế biểu hiện gen $L A G 3$ bất thường liên quan đến hoạt động của hệ miễn dịch bẩm sinh và hoạt động của các loại tế bào biểu hiện kháng nguyên (Liang et al., 2008).

Bên cạnh các gen kiểm soát miễn dịch, nhóm gen SH2 domain containing protein tyrosine phosphatase $(S H P)$ cũng có vai trò quan trọng không nhỏ trực tiếp điều hòa các quá trình sinh lý tế bào. Nhóm gen $S H P$ là những gen thuộc họ tín hiệu protein tyrosine phosphatase (PTP) điều hòa sự tăng sinh của tế bào ung thư thông qua các quá trình sinh lý tế bào như sự thuần thục, sự di cư và quá trình apoptosis (Wu et al., 2003). Nhóm gen này gồm hai loại gen chính là $S H P-1$ và $S H P-2$. SHP-1 có mặt ở hầu hết các loại tế bào gốc tạo máu và có vai trò ức chế khối u và tham gia điều hòa ngược hoạt động sinh học của tế bào bởi quá trình khử phosphoryl hóa một số tín hiệu phân tử như JAKs/STATs và PI3K/AKT/mTOR (Lorenz, 2009). Sự methyl hóa vùng promotor của gen $S H P-1$ làm giảm biểu hiện của gen này (Oka et al., 2002; Chim et al., 2004). Ngược với gen SHP-1, SHP-2 điều hòa thuận sự phát triển và chức năng của tế bào gốc tạo máu (Chan et al., 2006). SHP-2 hoạt hóa tín hiệu ERK thông qua hoạt động xúc tác làm tăng sự sống xót của tế bào ung thư (Dance et al., 2008) và không liên quan đến hoạt động kiềm soát của gen $P D-1$ (Rota et al., 2018). Chuột thiếu hụt gen $S H P-2$ chết sớm ở giai đoạn phôi thai. Biểu hiện bất thường của gen $S H P-2$ là một trong những nguyên nhân gây ra các loại bệnh mãn tính và ung thư (Chan et al., 2006; Tajan et al., 2015).

Nghiên cứu khác phát hiện các kháng nguyên được tiết ra từ tế bào ung thư vào máu bệnh nhân đang được sử dụng như là một trong những chỉ số sinh học phục vụ trong công tác chẩn đoán bệnh. Trong số các kháng nguyên ung thư, có protein cancer antigen 125 (CA125) được sử dụng rộng rãi trong phát hiện một số bệnh ung thư về cơ quan sinh sản của nữ giới, đặc biệt là ung thư buồng trứng (O'Brien et al., 2001). Nồng độ CA125 cao trong máu được phát hiện trong khoảng 50\% phụ nữ mắc ung thư buồng trứng giai đoạn sớm và $80 \%$ trường hợp giai đoạn muộn. Ngoài ra, nồng độ CA125 cũng tăng lên trong một số bệnh ung thư máu và cơ quan tạo máu và một số bệnh tự miễn (Birgen et al., 2005; $\mathrm{Wu}$ et al., 2016).

Mặc dù đã có nhiều nghiên cứu về đa hình và biểu hiện của các gen klotho, $C T L A-4, P D$ 1, LAG3, SHP1 và $S H P 2$ trên bệnh ung thư máu, nhưng nghiên cứu về mức độ biểu hiện của chúng và nồng độ của marker CA125 trên bệnh nhân THCVC Việt Nam chưa được chú ý đến. Trong nghiên cứu này, chúng tôi tiến hành tách chiết RNA tổng số và huyết thanh từ các mẫu máu, từ đó xác định mức độ biểu hiện của các gen trên và nồng độ CA125 phục vụ cho công tác chẩn đoán bệnh THCVC. 


\section{VẠT LIỆU VÀ PHƯƠNG PHÁP NGHIÊN CúU}

\section{Mẫu nghiên cứu}

Tại Bệnh viện Huyết học và truyền máu trung ương và Bệnh viện Quân Y 103, Hà Nội, Việt Nam, mẫu máu ngoại vi được thu thập từ 20 bệnh nhân chưa được điều trị chẩn đoán mắc bệnh tăng hồng cầu vô căn (THCVC). Các bệnh nhân đã được thăm khám lâm sàng, làm các xét nghiệm cận lâm sàng và giải phẫu bệnh để chẩn đoán xác định từng loại bệnh. Nhóm đối chứng gồm 10 người khỏe mạnh, trong đó không có người nào đang dùng thuốc hoặc bị bất kỳ bệnh cấp tính hay mạn tính nào khác. Tất cả bệnh nhân và tình nguyện viên đã ký văn bản đồng ý tham gia nghiên cứu. Các quy trình thí nghiệm và việc chăm sóc từng cá nhân được thực hiện theo luật pháp Việt Nam và đã được phê duyệt bởi Hội đồng $\mathrm{Y}$ đức của Viện Nghiên cứu hệ gen, Viện Hàn lâm Khoa học và Công nghệ Việt Nam.

\section{Phương pháp nghiên cứu}

Tổng lượng RNA được tách chiết bằng Trizol theo hướng dẫn của hãng Invitrogen. cDNA được tổng hợp từ RNA tổng số theo quy trình như sau: lấy $1 \mu \mathrm{g}$ RNA tổng số pha loãng vào nước cất DEPC thành $12,5 \mu \mathrm{l}$. Sau đó, thêm $1 \mu 1$ oligo-dT primer $(500 \mu \mathrm{g} / \mathrm{ml}$, Invitrogen) và ủ ở nhiệt độ $70^{\circ} \mathrm{C}$ trong 2 phút. Cho thêm vào ống đựng mẫu $2 \mu 110 x$ reaction buffer (Biolabs), $1 \mu \mathrm{l}$ dNTP mix (dATP,dCTP, dGTP, dTTP, 10 mM mỗi loại), $0,5 \mu 1$ chất ức chế Rnase (Roche), $0,1 \mu 1$ enzyme phiên mã ngược M-MuLV (Biolabs) và $2,9 \mu 1$ nước cất DEPC. Trộn đều mẫu sau đó ủ ở $42^{\circ} \mathrm{C}$ trong 1 tiếng. Để dừng phản ứng tổng hợp cDNA, các mẫu được ủ ơ $94^{\circ} \mathrm{C}$ trong 5 phút và dự trữ ở $-80^{\circ} \mathrm{C}$. Mẫu cDNA được phân tích mức độ biểu hiện các gen $C T L A-4$, $P D-1, L A G 3, S H P 1, S H P 2$ và $G A P D H$. Các primer được sử dụng bao gồm: CTLA-4: 5'-G TCCGGGTGACAGTGCTTCG-3' (forward) và 5'-CCAGGTAGTATGGCG GTGGG-3' (reverse); PD-1: 5'-TGCAGCTTCTCCAA CACATC-3' (forward) và 5'-CACGCTCA TGTGGAAGTCAC-3' (reverse); LAG-3: 5'CCTCACTGTTCTGGGTCTGG-3' (forward) và 5'-GGATATG GCAGGTGTAGGTC-3' (reverse); SHP-1 primer: 5'- GCC CAG TTC ATT GAA ACC AC-3' (forward) and 5'GAG GGA ACC CTT GCT CTT CT-3' (reverse); SHP-2 primer: 5'GAGAGCAATGACGGCAA GTCT-3' (forward) and 5'- CCTCCACCAACGTCGT ATTTC-3' (reverse) và GAPDH: 5'GGAGCGAGATCCCTCCAAA-3' (forward) and 5'-GGCTGTTGT CATACTTCTCAT-3' (reverse). Phản ứng quantitative PCR chứa 20 $\mu \mathrm{l}$ tổng thể tích gồm $2 \mu \mathrm{l}$ cDNA, $2.4 \mu \mathrm{l}$ $\mathrm{MgCl} 2(3 \mu \mathrm{M}), 1 \mu \mathrm{l}$ hai loại primer $(0.5 \mu \mathrm{M}$ mỗi loại), $2 \mu \mathrm{l}$ cDNA Master SybrGreen I mix (Roche Molecular Biochemicals) và $12.6 \mu \mathrm{l}$ nước DEPC. Đoạn cDNA được khuyếch đại ở $95^{\circ} \mathrm{C}$ trong 10 giây, $62^{\circ} \mathrm{C}$ trong 10 giây, và $72^{\circ} \mathrm{C}$ trong 16 giây, số vòng nhắc lại là 40 vòng. Phương pháp RT-PCR định lượng cho SHP-1 và SHP-2 được thực hiện trên hệ thống LightCycler System (Roche Diagnostics). Tỷ lệ biểu hiện tương quan giữa các gen nghiên cứu và gen GAPDH đối chứng được tính trên mỗi mẫu theo phương pháp ngưỡng chu trình.

\section{Phân tích nồng độ CA125 trong huyết thanh bằng kỹ thuật ELISA}

Huyết thanh được tách từ các mẫu máu và trữ đông ở (-) $20^{\circ} \mathrm{C}$ cho đến khi phân tích nồng độ CA125 bằng kỹ thuật ELISA. Để đo nồng độ CA125 trong huyết thanh, chúng tôi sử dụng kít thương mại Human Mucin 16 (CA125) ELISA kit (ThermoFisher Scientific) và cách làm dựa trên hướng dẫn sử dụng của công ty.

\section{Phương pháp xử lý số liệu}

Các nghiên cứu được lặp lại ít nhất 3 lần. Kết quả thí nghiệm là trung bình cộng của các giá trị và sự khác biệt giữa mẫu đổi chứng và mẫu bệnh nhân có ý nghĩa thống kê khi chỉ số $\mathrm{p}$ value $<0.05$ bằng phương pháp Student's two-tailed unpaired t-test.

\section{KẾT QUẢ VÀ THẢO LUẬN}

\section{Chỉ số xét nghiệm sinh hóa máu bệnh nhân THCVC}

Kết quả xét nghiệm sinh hóa máu chỉ ra tỷ lệ bệnh nhân THCVC có chỉ số axid uric, bilirubin gián tiếp, protein toàn phần, globulin 
và lactate dehydrogenase $(\mathrm{LDH})$ cao hơn người khỏe mạnh, tương ứng là $30 \%, 25 \%, 45 \%$, $25 \%$ và $60 \%$ (bảng 1 ). Nồng độ các chỉ số sinh học này tăng cao chỉ ra mức độ ảnh hưởng cao của bệnh đến sự tổn thương các cơ quan thận, gan và một số cơ quan khác. Nồng độ $\mathrm{LDH}$ tăng cao dẫn đến tăng nồng độ lactat trong máu và tổn thương mô. Chỉ số LDH tăng liên quan đến mức độ nặng của bệnh đã được chỉ ra trong một nghiên cứu gần đây trên bệnh nhân THCVC (Misawa et al., 2018). Ngoài ra, các chỉ số hóa sinh khác như ure, glucose, ferritin, AST và ALT cũng có một số bệnh nhân có các chỉ số này cao hơn bình thường.

Bảng 1. Tỷ lệ bệnh nhân THCVC có chỉ số xét nghiệm sinh hóa máu cao hơn bình thường

\begin{tabular}{|c|l|c|c|c|}
\hline STT & Chỉ số bệnh & $\begin{array}{c}\text { Bệnh nhân } \\
(\mathrm{n})\end{array}$ & $\begin{array}{c}\text { Bệnh nhân } \\
(\%)\end{array}$ & $\begin{array}{c}\text { Giá trị trung } \\
\text { bình }\end{array}$ \\
\hline 1 & Ure $(\mathrm{mmol} / \mathrm{l})$ & $3 / 20$ & 15 & $7,5 \pm 1,67$ \\
\hline 2 & Glucose $(\mathrm{mmol} / \mathrm{l})$ & $2 / 20$ & 10 & $5,36 \pm 0,7$ \\
\hline 3 & Creatinin $(\mu \mathrm{mol} / \mathrm{l})$ & $0 / 20$ & 0 & $79,8 \pm 20,5$ \\
\hline 4 & Axid uric $(\mu \mathrm{mol} / \mathrm{l})$ & $6 / 20$ & 30 & $336,8 \pm 112,2$ \\
\hline 5 & Bilirubin toàn phần $(\mu \mathrm{mol} / \mathrm{l})$ & $3 / 20$ & 15 & $14,15 \pm 4,8$ \\
\hline 6 & Bilirunbin trực tiếp $(\mu \mathrm{mol} / \mathrm{l})$ & $0 / 20$ & 0 & $2,4 \pm 1,2$ \\
\hline 7 & Bilirubin gián tiếp $(\mu \mathrm{mol} / \mathrm{l})$ & $5 / 20$ & 25 & $11,75 \pm 4,3$ \\
\hline 8 & Protein toàn phần $(\mathrm{g} / \mathrm{l})$ & $9 / 20$ & 45 & $80,8 \pm 3,9$ \\
\hline 9 & Albumin $(\mathrm{g} / \mathrm{l})$ & $0 / 20$ & 0 & $43,8 \pm 2,48$ \\
\hline 10 & Globulin $(\mathrm{g} / \mathrm{l})$ & $5 / 20$ & 25 & $37 \pm 4$ \\
\hline 11 & Chỉ số A/G & $0 / 20$ & 0 & $1,87 \pm 2,7$ \\
\hline 12 & Ferritin & $2 / 20$ & 10 & $255 \pm 230,69$ \\
\hline 13 & Calci ion hóa $(\mathrm{mmol} / \mathrm{l})$ & $0 / 20$ & 0 & $1,19 \pm 0,07$ \\
\hline 14 & AST $(\mathrm{GOT}) \mathrm{U} / \mathrm{l}-37^{\circ} \mathrm{C}$ & $2 / 20$ & 10 & $27,65 \pm 6,8$ \\
\hline 15 & ALT $(\mathrm{GPT}) \mathrm{U} / \mathrm{l}-37^{\circ} \mathrm{C}$ & $4 / 20$ & 20 & $29,3 \pm 23,2$ \\
\hline 16 & LDH U/l-37 $\mathrm{C}$ & $12 / 20$ & 60 & $600,4 \pm 238,1$ \\
\hline 17 & Canxi toàn phần $(\mathrm{mmol} / \mathrm{l})$ & $0 / 20$ & 0 & $2,35 \pm 0,12$ \\
\hline 18 & Định lượng Sắt huyết thanh $(\mu \mathrm{mol} / \mathrm{l})$ & $2 / 20$ & 10 & $15,47 \pm 6,7$ \\
\hline 19 & Na+ $(\mathrm{mmol} / \mathrm{l})$ & $0 / 20$ & 0 & $140,11 \pm 1,57$ \\
\hline 20 & K+(mmol/l) & $0 / 20$ & 0 & $3,91 \pm 0,34$ \\
\hline 21 & Cl- (mmol/l) & $0 / 20$ & 0 & $104,08 \pm 2,41$ \\
\hline
\end{tabular}

\section{Biểu hiện một số gen kiểm soát miễn dịch trên bệnh nhân THCVC}

Xét sự biểu hiện một số gen liên quan đến điều hòa hoạt động tế bào $\mathrm{T}$ bao gồm các gen $L A G 3, C T L A-4$ và $P D-1$ cho thấy các gen này đều có mức biểu hiện thấp hơn, trong đó biểu hiện của $L A G 3$ thấp hơn đáng kể so với mẫu đối chứng (Hình $1 \mathrm{~A})$, chứng tỏ hệ miễn dịch của bệnh nhân THCVC bị ảnh hưởng ít liên quan đến hoạt động kiểm soát miễn dịch của 3 gen $L A G 3, C T L A-4$ và $P D-1$. Ở bệnh nhân bạch cầu, biểu hiện của các gen này thường tăng cao và liên quan đến sự cạn kiệt về số lượng và chất lượng của tế bào $\mathrm{T}$ miễn dịch
(Buchbinder et al., 2015; Kitamura et al., 2015). Sự khác biệt về biểu hiện của các gen này trên bệnh nhân THCVC so với bệnh nhân bạch cầu đóng góp một phần vào công tác phân loại bệnh một cách chính xác. Bên cạnh đó, phân tích gen klotho trên bệnh nhân THCVC chỉ ra biểu hiện gen này giảm so với người khỏe. Gen klotho là gen tham gia điều hòa chống lão hóa, phản ứng viêm, quá trình apoposis và bệnh ung thư (Kuro-o, 2009; Markiewicz et al., 2016). Do đó, kết quả biểu hiện giảm các gen trên chỉ ra hệ miễn dịch đối kháng chưa hoạt động trong bệnh nhân THCVC (Liang et al., 2008). 
Tiếp theo, phân tích biểu hiện gen $S H P$-1 và $S H P-2$ liên quan đến hoạt động của tín hiệu tyrosine phosphatase cho thấy biểu hiện của hai gen $S H P-1$ và $S H P-2$ không thay đổi so với người khỏe, tuy nhiên biểu hiện của gen SHP-1 được chỉ ra bị bất hoạt trên bệnh nhân THCVC trên một nghiên cứu khác ở Hoa Kỳ (Wickrema et al., 1999). Biểu hiện của nhóm gen $S H P$ đa dạng phụ thuộc vào độ nặng của bệnh và liên quan đến hoạt động của tín hiệu phân tử JAK/STAT (Liu et al., 2011; Yang et al., 2015). Tương tự như sự khác biệt về biểu hiện gen kiểm soát miễn dịch trên, biểu hiện của 2 gen này trên bệnh nhân THCVC cũng khác biệt so với bệnh nhân bạch cầu (Oka et al., 2002; Chim et al., 2004). Điều này cho thây, biểu hiện của bệnh THCVC so với bệnh bạch cầu gần như khác biệt về đột biến một số gen chức năng và biểu hiện của một số gen liên quan đến hoạt động của tế bào miễn dịch.
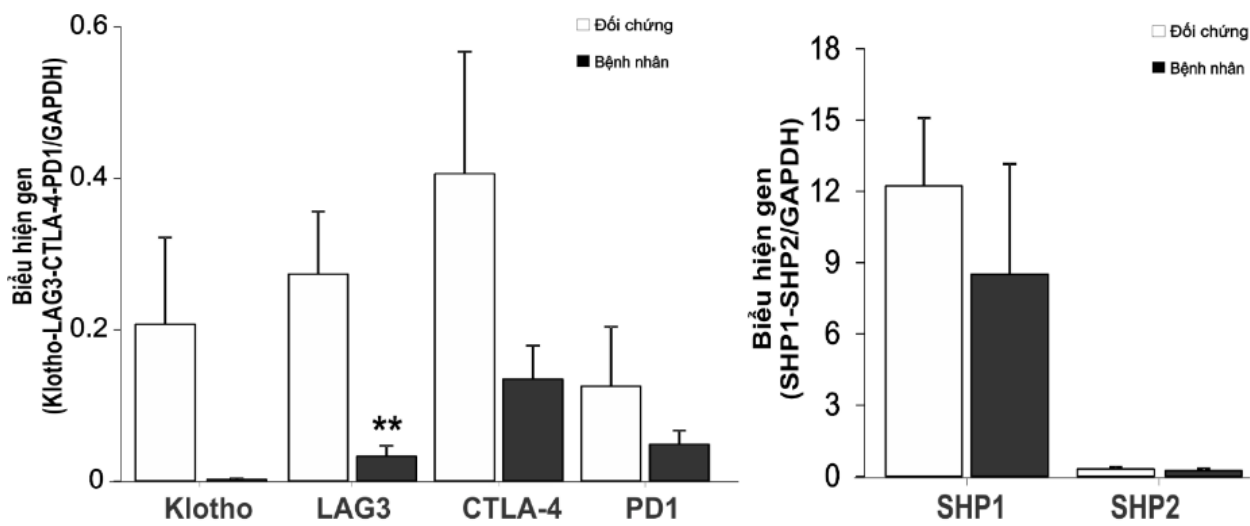

Hình 1. Biểu hiện gen klotho, LAG3, CTLA4, PD1, SHP1 và SHP2 trên bệnh nhân THCVC (cột màu đen) và người khỏe (cột màu trắng), ** $(\mathrm{p}<0.01)$ chỉ ra sự khác biệt có ý nghĩa thống kê giữa nhóm đối chứng và nhóm bệnh nhân (t-test)

Nồng độ CA125 trong huyết thanh bệnh nhân THCVC

Nồng độ trung bình CA125 ở người khỏe mạnh là $4.71 \mathrm{U} / \mathrm{ml}(0-12)$, trong khi đó ở bệnh nhân, nồng độ CA125 trung bình là $11.43 \mathrm{U} / \mathrm{ml}(0-62.2$, giá trị bình thường < $35 \mathrm{U} / \mathrm{ml})$ và sự khác biệt này có ý nghĩa thống kê $(\mathrm{P}=0.03)$ (hình 2). Nghiên cứu gần đây đã chỉ ra nồng độ CA125 tăng cao liên quan mật thiết với hiện tượng tăng tiểu cầu và độ nặng của bệnh ung thư máu (Gungor et al., 2009). CA125 đã được chỉ ra là một marker sinh học quan trọng liên quan đến sự tiến triển của nhiều bệnh ung thư, đặc biệt là ung thư buồng trứng và một số bệnh ung thư máu. Một nghiên cứu đánh giá mức độ CA125 ở những trẻ mắc bạch cầu lympho cấp tính và bệnh ung thư hạch cho thấy mức độ CA125 tăng cao ở những đứa trẻ mắc bệnh so với những đứa trẻ khỏe mạnh (Birgen et al., 2005). Trong nghiên cứu này, hầu hết các bệnh nhân có CA125 ở mức bình thường $(<35 \mathrm{U} / \mathrm{ml})$ và có 3 bệnh nhân có biểu hiện CA125 cao hơn mức bình thường.

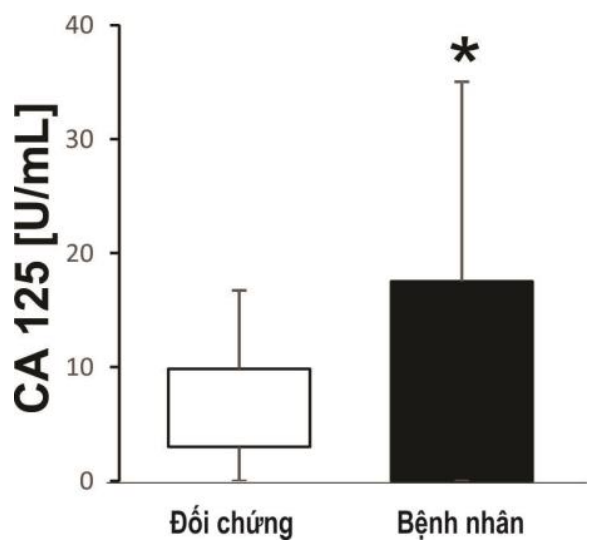

Hình 2. Kết quả đo nồng độ $\mathrm{CA} 125$ bằng phương pháp ELISA từ mẩu $\mathrm{ĐC}$ (cột trắng) và bị bệnh THCVC (cột đen). * (p < 0.05) chỉ ra sự khác biệt có ý nghĩa thống kê giữa nhóm đối chứng và nhóm bệnh nhân (t-test) 
Ngoài ra, phân tích mối liên quan giữa các chỉ số bệnh và biểu hiện các gen trên bệnh nhân THCVC, chúng tôi nhận thấy biểu hiện giảm của gen $L A G 3$ không liên quan đến sự tăng nồng độ các chỉ số hóa sinh trên. Tuy nhiên, 3 bệnh nhân có nồng độ CA 125 tăng cao hơn bình thường tỷ lệ thuận với các chỉ số sinh hóa máu $L D H, A S T$ và $A L T$, các marker này cũng tăng lên trong 3 bệnh nhân trên. Vì vậy, để xác định chính xác mối liên quan giữa nồng độ các chỉ số sinh học CA125, LDH, AST và $A L T$, chúng tôi cần nghiên cứu với cỡ mẫu nhiều hơn. Sự kết hợp giữa kết quả nghiên cứu với chẩn đoán lâm sàng và cận lâm sàng trước đó sẽ giúp cho việc chẩn đoán bệnh hiệu quả hơn.

\section{KẾT LUẬN}

Nghiên cứu này góp phần hiểu biết về mức độ biểu hiện của một số gen liên quan đến biểu hiện viểm, hoạt động kiểm soát miễn dịch và sự phát triển của tể bào ung thư cũng như đóng góp thêm những hiểu biết về sự khác biệt một số chỉ số sinh học giữa bệnh THCVC và bệnh bạch cầu. Biểu hiện các gen $L A G 3, C T L A-4$ và $P D-1$ giảm xuống ở bệnh nhân THCVC chỉ ra vai trò của hệ miễn dịch đối kháng hoạt động chưa hiệu quả trong người bệnh. Ngoài ra, kết quả mối liên quan tỷ lệ thuận giữa nồng độ CA125 và các chỉ số hóa sinh như $\mathrm{LDH}$, AST và ALT tăng cao trong 3 bệnh nhân gợi ý cho nghiên cứu tiếp theo với lượng mẫu lớn hơn giúp chẩn đoán phát hiện sớm ung thư THCVC.

Lời cảm ơn: Công trình hoàn thành với kinh phí được tài trợ bởi Chương trình phát triển khoa học cơ bản trong lĩnh vực Hóa học, Khoa học sự sống, Khoa học trái đất và Khoa học biển giai đoạn 2017-2025, Bộ Khoa học và Công nghệ.

\section{TÀI LIỆU THAM KHẢO}

Afrin L. B., 2011. Polycythemia from mast cell activation syndrome: lessons learned. Am. J. Med Sci., 342: 44-49.

Birgen D., Ertem U., Duru F. et al., 2005. Serum Ca 125 levels in children with acute leukemia and lymphoma. Leuk Lymphoma, 46: 1177-1181.
Buchbinder E., \& Desai A., 2015. CTLA-4 and PD-1 Pathways: Similarities, Differences, and Implications of Their Inhibition. American journal of clinical oncology 39:

Chan R. J., Li Y., Hass M. N. et al., 2006. Shp-2 heterozygous hematopoietic stem cells have deficient repopulating ability due to diminished self-renewal. Exp. Hematol., 34: 1230-1239.

Chim C. S., Fung T. K., Cheung W. C., Liang R., \& Kwong Y. L., 2004. SOCS1 and SHP1 hypermethylation in multiple myeloma: implications for epigenetic activation of the Jak/STAT pathway. Blood, 103: 4630-4635.

Dance M., Montagner A., Salles J. P., Yart A., \& Raynal P., 2008. The molecular functions of Shp2 in the Ras/Mitogenactivated protein kinase (ERK1/2) pathway. Cell Signal., 20: 453-459.

Gungor T., Kanat-Pektas M., Sucak A., \& Mollamahmutoglu L., 2009. The role of thrombocytosis in prognostic evaluation of epithelial ovarian tumors. Arch Gynecol Obstet, 279: 53-56.

Hantschel O., Warsch W., Eckelhart E. et al., 2012. BCR-ABL uncouples canonical JAK2-STAT5 signaling in chronic myeloid leukemia. Nature chemical biology, 8: 285-293.

Hehlmann R., Hochhaus A., Baccarani M., \& European L., 2007 Chronic myeloid leukaemia. Lancet, 370: 342-350.

Kitamura T., Qian B. Z., \& Pollard J. W., 2015. Immune cell promotion of metastasis. Nat. Rev. Immunol., 15: 73-86.

Kuro-o M., 2009. Klotho and aging. Biochim Biophys Acta, 1790: 1049-1058.

Liang B., Workman C., Lee J. et al., 2008. Regulatory $\mathrm{T}$ cells inhibit dendritic cells by lymphocyte activation gene-3 engagement of MHC class II. J. Immunol., 180: 5916-5926. 
Liu X., \& Qu C. K., 2011. Protein Tyrosine Phosphatase SHP-2 (PTPN11) in Hematopoiesis and Leukemogenesis. $J$ Signal Transduct, 2011: 195239.

Lorenz U., 2009. SHP-1 and SHP-2 in T cells: two phosphatases functioning at many levels. Immunol Rev., 228: 342-359.

Markiewicz M., Panneerselvam K., \& Marks N., 2016. Role of Klotho in migration and proliferation of human dermal microvascular endothelial cells. Microvasc Res., 107: 76-82.

Misawa K., Yasuda H., Araki M. et al., 2018. Mutational subtypes of JAK2 and CALR correlate with different clinical features in Japanese patients with myeloproliferative neoplasms. Int. J. Hematol., 107: 673-680.

O'Brien T., Beard J., Underwood L. et al., 2001. The CA 125 Gene: An Extracellular Superstructure Dominated by Repeat Sequences. Tumour biology: the journal of the International Society for Oncodevelopmental Biology and Medicine, 22: 348-366.

Oka T., Ouchida M., Koyama M. et al., 2002. Gene silencing of the tyrosine phosphatase SHP1 gene by aberrant methylation in leukemias/lymphomas. Cancer Res., 62: 6390-6394.
Rota G., Niogret C., Dang A. T. et al., 2018. Shp-2 Is Dispensable for Establishing $\mathrm{T}$ Cell Exhaustion and for PD-1 Signaling In Vivo. Cell Rep., 23: 39-49.

Siegel F. P., Tauscher J., \& Petrides P. E., 2013. Aquagenic pruritus in polycythemia vera: characteristics and influence on quality of life in 441 patients. Am. J. Hematol., 88: 665-669.

Tajan M., de Rocca Serra A., Valet P., Edouard T., \& Yart A., 2015. SHP2 sails from physiology to pathology. Eur. J. Med Genet, 58: 509-525.

Wickrema A., Chen F., Namin F. et al., 1999. Defective expression of the SHP-1 phosphatase in polycythemia vera. Exp Hematol., 27: 1124-1132.

Wu J. Z., Tian T., Huang Y. et al., 2016. Serum carbohydrate antigen 125 concentration as a superior predictor for serosal effusion at diagnosis and a prognostic factor in diffuse large B-cell lymphoma. Cancer Biomark, 17: 205-212.

Yang J.-J., Chen H., Zheng X.-Q. et al., 2015. Methylated Alteration of SHP1 Complements Mutation of JAK2 Tyrosine Kinase in Patients with Myeloproliferative Neoplasm. Asian Pacific journal of cancer prevention: APJCP, 16: 2219-2225. 